International Mathematical Forum, Vol. 8, 2013, no. 25, 1233 - 1241

HIKARI Ltd, www.m-hikari.com

http://dx.doi.org/10.12988/imf.2013.3599

\title{
The Split Common Fixed Point Problem for Asymptotically Quasi-Nonexpansive Mappings in the Intermediate Sense
}

\author{
Zhaoli Ma \\ School of Information Engineering \\ The College of Arts and Sciences \\ Yunnan Normal University \\ Kunming, Yunnan, 650222, P.R. China \\ kmszmzl@126.com \\ Yunhe Zhao ${ }^{1}$ \\ College of Statistics and Mathematics \\ Yunnan University of Finance and Economics \\ Kunming, Yunnan, 650221, P.R. China \\ zyh961019@163.com
}

Copyright (c) 2013 Zhaoli Ma and Yunhe Zhao. This is an open access article distributed under the Creative Commons Attribution License, which permits unrestricted use, distribution, and reproduction in any medium, provided the original work is properly cited.

\begin{abstract}
In this paper, we introduce an algorithm for solving the split common fixed point problem for asymptotically quasi-nonexpansive mapping in the intermediate sense in Hilbert spaces. The strong and weak convergence of the presented algorithm to split common fixed point are obtained. The results presented in this paper improve and extend some recent corresponding results announced by some authors.
\end{abstract}

Mathematics Subject Classifications: 47H09, 47J25

Keywords: Split common fixed point problem; asymptotically Quasi- nonexpansive mapping in the intermediate sense; Convergence; Hilbert space

\footnotetext{
${ }^{1}$ The corresponding author: zyh961019@163.com. This work was supported by the Youth Scientific Reserch Foundation of Yunnan Normal University (No. 12ZQ14).
} 


\section{Introduction and Preliminaries}

Let $H_{1}$ and $H_{2}$ be real Hilbert spaces with inner product $\left.<\cdot, \cdot\right\rangle$ and norm $\|\cdot\|$. Let $C$ and $Q$ be nonempty closed convex subsets of $H_{1}$ and $H_{2}$, respectively. The split feasibility problem $(S F P)$ is formulated as finding a point $q$ with the property

$$
q \in C \text { and } A q \in Q \text {, }
$$

where $A: H_{1} \rightarrow H_{2}$ is a bounded linear operator.

The SFP in finite-dimensional Hilbert spaces was first introduced by Censor and Elfving [1] for modeling inverse problems which arise from phase retrievals and in medical image reconstruction [2]. Recently, it has been found that the $S F P$ can also be used in various disciplines such as image restoration, computer tomograph, and radiation therapy treatment planning $[1,3-7]$.

The split common fixed point problem (SCFP) is a generalization of the split feasibility problem (SFP) and the convex feasibility problem (CFP), see [4]. Let $S: H_{1} \rightarrow H_{1}$ and $T: H_{2} \rightarrow H_{2}$ be two mappings satisfying $F(S)=\left\{x \in H_{1}: S x=x\right\} \neq \phi$ and $F(T)=\left\{x \in H_{2}: T x=x\right\} \neq \phi$, respectively. The split common fixed point problem for mappings $S$ and $T$ is to find a point $q \in H_{1}$ with the property:

$$
q \in F(S) \text { and } A q \in F(T) .
$$

where $A$ is a bounded linear operator from $H_{1}$ to $H_{2}$. We use $\Gamma$ to denote the set of solutions of $S C F P(1.2)$.

The split common fixed problem for quasi-nonexpansive mappings and demicontractive mappings in Hilbert space was first introduced and studied by Moudafi [8,9]. In [9], Moudafi proposed the following iterative algorithm for solving split common fixed problem of quasi-nonexpansive mappings: for arbitrarily chosen $x_{1} \in H_{1}$,

$$
\left\{\begin{array}{l}
u_{n}=x_{n}+\gamma \beta A^{*}(T-I) A x_{n}, \\
x_{n+1}=\left(1-\alpha_{n}\right) u_{n}+\alpha_{n} U u_{n}, \quad n \in N
\end{array}\right.
$$

and proved that $\left\{x_{n}\right\}$ converges weakly to a split common fixed point $x^{*} \in \Gamma$, where $U: H_{1} \rightarrow H_{1}$ and $T: H_{2} \rightarrow H_{2}$ are two quasi-nonexpansive mappings, $A: H_{1} \rightarrow H_{2}$ is a bounded linear operator, $\lambda$ is the spectral radius of the operator $A A^{*}$.

Then, Qin etc. [10] obtained the weak and strong convergence theorems of the split feasibility problem for asymptotically quasi-nonexpansive mappings, their results improve and extend the result of Moudafi [9].

A mapping $T: C \rightarrow E$ is said to be nonexpansive if

$$
\|T x-T y\| \leq\|x-y\|, \quad \forall x, y \in C .
$$

A mapping $T$ is said to be quasi-nonexpansive if $F(T) \neq \emptyset$ and

$$
\|p-T y\| \leq\|p-y\|, \quad \forall p \in F(T), \forall y \in D .
$$

$T$ is said to be asymptotically nonexpansive if there exists a sequence $\left\{\mu_{n}\right\} \subset[0, \infty)$ with $\mu_{n} \rightarrow 0$ as $n \rightarrow \infty$ such that

$$
\left\|T^{n} x-T^{n} y\right\| \leq\left(1+\mu_{n}\right)\|x-y\|, \quad \forall x, y \in D, \forall n \geq 1 .
$$


$T$ is said to be asymptotically quasi-nonexpansive if $F(T) \neq \emptyset$ and there exists a sequence $\left\{\mu_{n}\right\} \subset[0, \infty)$ with $\mu_{n} \rightarrow 0$ as $n \rightarrow \infty$ such that

$$
\left\|p-T^{n} y\right\| \leq\left(1+\mu_{n}\right)\|p-y\|, \quad \forall p \in F(T), \forall y \in D, \forall n \geq 1 .
$$

Obviously, the class of asymptotically quasi-nonexpansive mappings contains properly the class of quasi-nonexpansive mappings as a subclass, but the converse may not be true.

Asymptotically (quasi-) nonexpansive mapping in the intermediate sense which was first considered by Bruck et al. [11]. Very recently Qin and Wang [12] introduced the concept of the asymptotically (quasi-) nonexpansive mapping in the intermediate sense as following:

(1) $T$ is said to be asymptotically nonexpansive mapping in the intermediate sense if it is continuous and the following inequality holds:

$$
\limsup _{n \rightarrow \infty} \sup _{x, y \in C}\left(\left\|T^{n} x-T^{n} y\right\|-\|x-y\|\right) \leq 0
$$

It is worth mentioning that the class of asymptotically nonexpansive mappings in the intermediate sense may not be Lipschitzian continuous; see [11, 13, 14].

(2) $T$ is said to be asymptotically quasi-nonexpansive in the intermediate sense if $F(T) \neq \emptyset$ and the following inequality holds:

$$
\limsup _{n \rightarrow \infty} \sup _{p \in F(T), y \in C}\left(\left\|p-T^{n} y\right\|-\|p-y\|\right) \leq 0 .
$$

If we define

$$
\xi_{n}=\max \left\{0, \sup _{p \in F(T), y \in C}\left(\left\|p-T^{n} y\right\|-\|p-y\|\right)\right\},
$$

then $\xi_{n} \rightarrow 0$, as $n \rightarrow \infty$. It follows that (1.8) is reduced to

$$
\left\|p-T^{n} y\right\| \leq\|p-y\|+\xi_{n}, \forall p \in F(T), y \in C, \forall n \geq 1
$$

Motivated and inspired by the work of Moudafi [9], Qin and Wang [12], in this paper, we introduce an algorithm for study the $S C F P(1.2)$ of asymptotically quasi-nonexpansive mapping in the intermediate sense in Hilbert spaces, and obtain some the strong and weak convergence of the presented algorithm to some $q \in \Gamma$. The results presented in this paper improve and extend some recent corresponding results announced by some authors.

We recall some definitions, notations and conclusions which will be used in proving our main results.

Let $E$ be a Banach space. A mapping $T: E \rightarrow E$ is said to be demi-closed at origin, if for any sequence $\left\{x_{n}\right\} \subset E$ with $x_{n} \rightarrow x^{*}$ and $\left\|(I-T) x_{n}\right\| \rightarrow 0$, then $x^{*}=T x^{*}$.

A Banach space $E$ is said to satisfy Opial's condition, if for any sequence $\left\{x_{n}\right\}$ in $E$, $x_{n} \rightarrow x^{*}$ implies that

$$
\liminf _{n \rightarrow \infty}\left\|x_{n}-x^{*}\right\|<\liminf _{n \rightarrow \infty}\left\|x_{n}-y\right\|, \quad \forall y \in E \text { with } y \neq x^{*}
$$


It is well known that every Hilbert space satisfies Opial's condition.

A mapping $T: H \rightarrow H$ is said to be semi-compact, if for any bounded sequence $\left\{x_{n}\right\} \subset H$ with $\lim _{n \rightarrow \infty}\left\|x_{n}-T x_{n}\right\|=0$, then there exists a subsequence $\left\{x_{n_{i}}\right\}$ of $\left\{x_{n}\right\}$ such that $\left\{x_{n_{i}}\right\}$ converges strongly to some point $q \in H$.

By using the well-known inequality $\langle x, y\rangle=\frac{1}{2}\|x\|^{2}+\frac{1}{2}\|y\|^{2}-\frac{1}{2}\|x-y\|^{2}$ in Hilbert spaces, we can easily show the following proposition. The proof is omitted.

Proposition 1.1 Let $T: H \rightarrow H$ be a asymptotically quasi- nonexpansive mapping in the intermediate sense in Hilbert space. Then for each $q \in F(T)$ and $x \in H$, the following inequalities hold

$$
\begin{gathered}
\left\langle x-T^{n} x, x-q\right\rangle \geq \frac{1}{2}\left\|x-T^{n} x\right\|^{2}-\frac{\xi_{n}}{2} ; \\
\left\langle x-T^{n} x, q-T^{n} x\right\rangle \leq \frac{1}{2}\left\|x-T^{n} x\right\|^{2}+\frac{\xi_{n}}{2} .
\end{gathered}
$$

Lemma 1.2[15] Let $\left\{a_{n}\right\}$ and $\left\{b_{n}\right\}$ be two sequences of nonnegative real numbers satisfying the inequality:

$$
a_{n+1} \leq a_{n}+b_{n}, \text { for alln } \geq 0 .
$$

If $\sum_{n=1}^{\infty} b_{n}<\infty$, then the $\lim _{n \rightarrow \infty} a_{n}$ exists.

\section{Main Results}

Theorem 2.1. Let $H_{1}$ and $H_{2}$ be two real Hilbert spaces, and $A: H_{1} \rightarrow H_{2}$ is a bounded linear operator. Let $S: H_{1} \rightarrow H_{1}$ be an uniformly $L_{1}$-Lipschitzian and asymptotically quasi- nonexpansive mapping in the intermediate sense with sequence $\left\{\xi_{n}^{(1)}\right\}$ and $T: H_{2} \rightarrow H_{2}$ be an uniformly $L_{2}$-Lipschitzian and asymptotically quasinonexpansive mapping in the intermediate sense with sequence $\left\{\xi_{n}^{(2)}\right\}$. For arbitrarily chosen $x_{1} \in H_{1},\left\{x_{n}\right\}$ is defined as follows:

$$
\left\{\begin{array}{l}
u_{n}=x_{n}+\gamma A^{*}\left(T^{n}-I\right) A x_{n} \\
x_{n+1}=\left(1-\alpha_{n}\right) u_{n}+\alpha_{n} S^{n} y_{n}, \quad n \geq 1
\end{array}\right.
$$

where $\left\{\alpha_{n}\right\}$ is a sequence in $[0,1]$ and $\gamma>0$ is a constant satisfying the following conditions:

(1) $C:=F(S) \neq \emptyset, Q:=F(T) \neq \emptyset$;

(2) $\xi_{n}=\max \left\{\xi_{n}^{(1)}, \xi_{n}^{(2)}\right\}, n \geq 1$, and $\sum_{n=1}^{\infty} \xi_{n}<\infty$

(3) $\alpha_{n} \in(\alpha, 1-\alpha)$ for some $\alpha \in(0,1)$ and $\gamma \in\left(0, \frac{1}{\|A\|^{2}}\right)$. 
If $T$ and $S$ both are demi-closed at origin and $\Gamma \neq \emptyset$, then

(I) the sequences $\left\{x_{n}\right\}$ converges weakly to a split common fixed point $q \in \Gamma$.

(II) In addition, if $S$ is also semi-compact, then $\left\{x_{n}\right\}$ and $\left\{u_{n}\right\}$ both converge strongly to a $q \in \Gamma$.

Proof. (I) The proof will be divided 4 steps.

step 1. We prove that for each $q \in \Gamma, \lim _{n \rightarrow \infty}\left\|x_{n}-q\right\|$ and $\lim _{n \rightarrow \infty}\left\|u_{n}-q\right\|$ exist.

For any given $q \in \Gamma$, i.e., $q \in F(S)=C$ and $A q \in F(T)=Q$. It follows from proposition 1.2 and (2.1) that

$$
\begin{aligned}
\left\|x_{n+1}-q\right\|^{2} & \leq\left\|u_{n}-q-\alpha_{n}\left(u_{n}-S^{n} u_{n}\right)\right\|^{2} \\
& =\left\|u_{n}-q\right\|^{2}-2 \alpha_{n}\left\langle u_{n}-q, u_{n}-S^{n} u_{n}\right\rangle+\alpha_{n}^{2}\left\|u_{n}-S^{n} u_{n}\right\|^{2} \\
& \leq\left\|u_{n}-q\right\|^{2}-\alpha_{n}\left(1-\alpha_{n}\right)\left\|u_{n}-S^{n} u_{n}\right\|^{2}+\alpha_{n} \xi_{n}^{(1)}
\end{aligned}
$$

and

$$
\begin{aligned}
\left\|u_{n}-q\right\|^{2}= & \left\|x_{n}+\gamma A^{*}\left(T^{n}-I\right) A x_{n}-q\right\|^{2} \\
= & \left\|x_{n}-q\right\|^{2}+\gamma^{2}\left\|A^{*}\left(T^{n}-I\right) A x_{n}\right\|^{2}+2 \gamma<x_{n}-q, A^{*}\left(T^{n}-I\right) A x_{n}> \\
= & \left\|x_{n}-q\right\|^{2}+\gamma^{2}<\left(T^{n}-I\right) A x_{n}, A A^{*}\left(T^{n}-I\right) A x_{n}> \\
& +2 \gamma<x_{n}-q, A^{*}\left(T^{n}-I\right) A x_{n}>,
\end{aligned}
$$

where

$$
\begin{aligned}
\gamma^{2}<\left(T^{n}-I\right) A x_{n}, A A^{*}\left(T^{n}-I\right) A x_{n}> & \leq\|A\|^{2} \gamma^{2}<\left(T^{n}-I\right) A x_{n},\left(T^{n}-I\right) A x_{n}> \\
& \leq\|A\|^{2} \gamma^{2}\left\|\left(T^{n}-I\right) A x_{n}\right\|^{2},
\end{aligned}
$$

and

$$
\begin{aligned}
2 \gamma<x_{n}-q, & A^{*}\left(T^{n}-I\right) A x_{n}> \\
& =2 \gamma<A\left(x_{n}-q\right),\left(T^{n}-I\right) A x_{n}> \\
& =2 \gamma<A\left(x_{n}-q\right)+\left(T^{n}-I\right) A x_{n}-\left(T^{n}-I\right) A x_{n},\left(T^{n}-I\right) A x_{n}> \\
& =2 \gamma\left(<T^{n}\left(A x_{n}\right)-A q,\left(T^{n}-I\right) A x_{n}>-\left\|\left(T^{n}-I\right) A x_{n}\right\|^{2}\right) .
\end{aligned}
$$

Using (1.11), we have

$$
\begin{aligned}
2 \gamma\left(<T^{n}\right. & \left.\left(A x_{n}\right)-A q,\left(T^{n}-I\right) A x_{n}>-\left\|\left(T^{n}-I\right) A x_{n}\right\|^{2}\right) \\
& \leq \gamma\left\|\left(T^{n}-I\right) A x_{n}\right\|^{2}+\gamma \xi_{n}^{(2)}-2 \gamma\left\|\left(T^{n}-I\right) A x_{n}\right\|^{2} \\
& \leq-\gamma\left\|\left(T^{n}-I\right) A x_{n}\right\|^{2}+\gamma \xi_{n}^{(2)} .
\end{aligned}
$$

Substituting (2.4) and (2.6) into(2.3) and simplifying, we obtain

$$
\begin{gathered}
\left\|u_{n}-q\right\|^{2} \leq\left\|x_{n}-q\right\|^{2}+\gamma^{2}\|A\|^{2}\left\|\left(T^{n}-I\right) A x_{n}\right\|^{2}-\gamma\left\|\left(T^{n}-I\right) A x_{n}\right\|^{2}+\gamma \xi_{n}^{(2)} \\
\leq\left\|x_{n}-q\right\|^{2}-\gamma\left(1-\gamma\|A\|^{2}\right)\left\|\left(T^{n}-I\right) A x_{n}\right\|^{2}+\gamma \xi_{n}^{(2)} .
\end{gathered}
$$

Substituting (2.7) into (2.2) and simplifying, we have

$$
\begin{aligned}
\left\|x_{n+1}-q\right\|^{2} \leq & \left\|x_{n}-q\right\|^{2}-\gamma\left(1-\gamma\|A\|^{2}\right)\left\|\left(T^{n}-I\right) A x_{n}\right\|^{2}+\gamma \xi_{n}^{(2)} \\
& -\alpha_{n}\left(1-\alpha_{n}\right)\left\|u_{n}-S^{n} u_{n}\right\|^{2}+\alpha_{n} \xi_{n}^{(1)} \\
= & \left\|x_{n}-q\right\|^{2}-\gamma\left(1-\gamma\|A\|^{2}\right)\left\|\left(T^{n}-I\right) A x_{n}\right\|^{2} \\
& -\alpha_{n}\left(1-\alpha_{n}\right)\left\|u_{n}-S^{n} u_{n}\right\|^{2}+\alpha_{n} \xi_{n}^{(1)}+\gamma \xi_{n}^{(2)},
\end{aligned}
$$


Since $\xi_{n}=\max \left\{\xi_{n}^{(1)}, \xi_{n}^{(2)}\right\}$ and $\sum_{n=1}^{\infty} \xi_{n}<\infty$, we have

$$
\left\|x_{n+1}-q\right\|^{2} \leq\left\|x_{n}-q\right\|^{2}+\xi_{n} .
$$

Therefore, it follows from Lemma 1.2 that $\lim _{n \rightarrow \infty}\left\|x_{n}-q\right\|$ exists.

We now prove that for each $q \in \Gamma$, the limit $\lim _{n \rightarrow \infty}\left\|u_{n}-q\right\|$ exists.

Since $\lim _{n \rightarrow \infty}\left\|x_{n}-q\right\|$ exists, from (2.8), we have

$$
\begin{aligned}
& \gamma\left(1-\gamma\|A\|^{2}\right)\left\|\left(T^{n}-I\right) A x_{n}\right\|^{2}+\alpha_{n}\left(1-\alpha_{n}\right)\left\|u_{n}-S^{n} u_{n}\right\|^{2} \\
& \leq\left\|x_{n}-q\right\|^{2}-\left\|x_{n+1}-q\right\|^{2}+\alpha_{n} \xi_{n}^{(1)}+\gamma \xi_{n}^{(2)} \rightarrow 0, \text { as } n \rightarrow \infty .
\end{aligned}
$$

This implies that

$$
\lim _{n \rightarrow \infty}\left\|u_{n}-S^{n} u_{n}\right\|=0,
$$

and

$$
\lim _{n \rightarrow \infty}\left\|\left(T^{n}-I\right) A x_{n}\right\|=0 .
$$

Thus, since $\lim _{n \rightarrow \infty}\left\|x_{n}-q\right\|$ exists, it follows from (2.3) and (2.11) that $\lim _{n \rightarrow \infty}\left\|u_{n}-q\right\|$ exists and $\lim _{n \rightarrow \infty}\left\|x_{n}-q\right\|=\lim _{n \rightarrow \infty}\left\|u_{n}-q\right\|$.

Step 2. Now we prove that $\lim _{n \rightarrow \infty}\left\|x_{n+1}-x_{n}\right\|=0$ and $\lim _{n \rightarrow \infty}\left\|u_{n+1}-u_{n}\right\|=0$.

It follows from (2.1) that

$$
\begin{aligned}
\left\|x_{n_{+}}-x_{n}\right\| & =\left\|\left(1-\alpha_{n}\right) u_{n}+\alpha_{n} S^{n} u_{n}-x_{n}\right\| \\
& =\left\|\left(1-\alpha_{n}\right)\left(x_{n}+\gamma A^{*}\left(T^{n}-I\right) A x_{n}\right)+\alpha_{n} S^{n} u_{n}-x_{n}\right\| \\
& =\left\|\left(1-\alpha_{n}\right) \gamma A^{*}\left(T^{n}-I\right) A x_{n}+\alpha_{n}\left(S^{n} u_{n}-x_{n}\right)\right\| \\
& =\left\|\left(1-\alpha_{n}\right) \gamma A^{*}\left(T^{n}-I\right) A x_{n}+\alpha_{n}\left(S^{n} u_{n}-u_{n}\right)+\alpha_{n}\left(u_{n}-x_{n}\right)\right\| \\
& =\left\|\left(1-\alpha_{n}\right) \gamma A^{*}\left(T^{n}-I\right) A x_{n}+\alpha_{n}\left(S^{n} u_{n}-u_{n}\right)+\alpha_{n} \gamma A^{*}\left(T^{n}-I\right) A x_{n}\right\| \\
& =\left\|\gamma A^{*}\left(T^{n}-I\right) A x_{n}+\alpha_{n}\left(S^{n} u_{n}-u_{n}\right)\right\| .
\end{aligned}
$$

In view of (2.10) and (2.11) we have that

$$
\lim _{n \rightarrow \infty}\left\|x_{n_{+}}-x_{n}\right\|=0 .
$$

Similarly, it follows from (2.1), (2.11) and (2.12) that

$$
\begin{aligned}
\left\|u_{n+1}-u_{n}\right\|= & \left\|x_{n+1}+\gamma A^{*}\left(T^{n+1}-I\right) A x_{n+1}-\left(x_{n}+\gamma A^{*}\left(T^{n}-I\right) A x_{n}\right)\right\| \\
= & \left\|x_{n+1}-x_{n}\right\|+\gamma\left\|A^{*}\left(T^{n+1}-I\right) A x_{n+1}\right\| \\
& +\gamma \| A^{*}\left(T^{n}-I\right) A x_{n} \rightarrow 0, \quad(n \rightarrow \infty)
\end{aligned}
$$

Step 3. Next, we prove that $\left\|u_{n}-S u_{n}\right\| \rightarrow 0$ and $\left\|A x_{n}-T A x_{n}\right\| \rightarrow 0$ as $n \rightarrow \infty$.

Since $S$ is uniformly $L_{1}$-Lipschitzian continuous, we have

$$
\begin{aligned}
\left\|u_{n}-S u_{n}\right\| \leq & \left\|u_{n}-S^{n} u_{n}\right\|+\left\|S^{n} u_{n}-S u_{n}\right\| \\
\leq & \left\|u_{n}-S^{n} u_{n}\right\|+L_{1}\left\|S^{n-1} u_{n}-u_{n}\right\| \\
\leq & \left\|u_{n}-S^{n} u_{n}\right\|+L_{1}\left(\left\|S^{n-1} u_{n}-S^{n-1} u_{n-1}\right\|+\left\|S^{n-1} u_{n-1}-u_{n}\right\|\right) \\
\leq & \left\|u_{n}-S^{n} u_{n}\right\|+L_{1}^{2}\left\|u_{n}-u_{n-1}\right\| \\
& +L_{1}\left(\left\|S^{n-1} u_{n-1}-u_{n-1}\right\|+\left\|u_{n-1}-u_{n}\right\|\right) \\
\leq & \left\|u_{n}-S^{n} u_{n}\right\|+L_{1}\left(1+L_{1}\right)\left\|u_{n}-u_{n-1}\right\|+L_{1}\left\|S^{n-1} u_{n-1}-u_{n-1}\right\| .
\end{aligned}
$$


by (2.10) and (2.13), we obtain

$$
\left\|u_{n}-S u_{n}\right\| \rightarrow 0, \quad(n \rightarrow \infty)
$$

Similarly, we have

$$
\left\|A x_{n}-T A x_{n}\right\| \rightarrow 0, \quad(n \rightarrow \infty) .
$$

Step 4. Finally, we prove that $x_{n} \rightarrow q$ and $u_{n} \rightarrow q$, where $q \in \Gamma$

Since $\left\{u_{n}\right\}$ is bounded, there exists a subsequence $\left\{u_{n_{i}}\right\} \subset\left\{u_{n}\right\}$ such that $u_{n_{i}} \rightarrow$ $q\left(\right.$ some point in $\left.H_{1}\right)$. From $(2.15)$ we have $\lim _{i \rightarrow \infty}\left\|u_{n_{i}}-S u_{n_{i}}\right\|=0$. Since $S$ is demiclosed at zero, we know that $q \in F(S)$. Moreover, it follows from (2.1) and (2.11) that

$$
x_{n_{i}}=u_{n_{i}}-\gamma A^{*}\left(T^{n_{i}}-I\right) A x_{n_{i}} \rightarrow q
$$

Since $A$ is a linear bounded operator, it gets $A x_{n_{i}} \rightarrow A q$. In view of (2.16) we have $\lim _{i \rightarrow \infty}\left\|A x_{n_{i}}-T A x_{n_{i}}\right\|=0$.

Again since $T$ is demi-closed at zero, we know that $A q \in F(T)$. This implies that $q \in \Gamma$.

Assume that there exists another subsequence $\left\{u_{n_{k}}\right\}$ of $\left\{u_{n}\right\}$ such that $\left\{u_{n_{k}}\right\}$ converges weakly to a point $p \in H$ with $p \neq q$. Using the same argument above, we know that $p \in \Gamma$. Since each Hilbert space possesses Opial property, we have

$$
\begin{aligned}
\liminf _{i \rightarrow \infty}\left\|u_{n_{i}}-q\right\| & <\liminf _{i \rightarrow \infty}\left\|u_{n_{i}}-p\right\|=\lim _{n \rightarrow \infty}\left\|u_{n}-p\right\| \\
& =\liminf _{k \rightarrow \infty}\left\|u_{n_{k}}-p\right\|<\liminf _{k \rightarrow \infty}\left\|u_{n_{k}}-q\right\| \\
& =\lim _{n \rightarrow \infty}\left\|u_{n}-q\right\|=\liminf _{i \rightarrow \infty}\left\|u_{n_{i}}-q\right\|,
\end{aligned}
$$

which is a contradiction. This implies that $\left\{u_{n}\right\}$ converges weakly to the point $q \in \Gamma$. Since $x_{n}=u_{n}-\gamma A^{*}\left(T^{n}-I\right) A x_{n}$, we know that $\left\{x_{n}\right\}$ converges weakly to $q \in \Gamma$. The proof of conclusion(I) is completed.

\section{The Proof of conclusion (II)}

Since $S$ is semi-compact, it follows from (2.15) that there exists a subsequence of $\left\{u_{n_{i}}\right\}$, (Without loss of generality, we still denote it by $\left\{u_{n_{i}}\right\}$ ) such that $\left\{u_{n_{i}}\right\} \rightarrow p \in H$ (some point in $\mathrm{H})$. Since $\left\{u_{n_{i}}\right\} \rightarrow q$, this implies that $q=p$. And so $\left\{u_{n_{i}}\right\} \rightarrow q \in \Gamma$ as $i \rightarrow \infty$. Since $\lim _{n \rightarrow \infty}\left\|x_{n}-q\right\|$ and $\lim _{n \rightarrow \infty}\left\|u_{n}-q\right\|$ exist, and $\lim _{n \rightarrow \infty}\left\|x_{n}-q\right\|=\lim _{n \rightarrow \infty}\left\|u_{n}-q\right\|$ for each $q \in \Gamma$. This implies that $\left\{x_{n}\right\}$ and $\left\{u_{n}\right\}$ both converge strongly to a $q \in \Gamma$. The proof is completed.

Remark 2.2. Theorem 2.1 improve and extend the corresponding results of Moudafi [9], and Qin and Wang [10] and others.

\section{References}

[1] Y. Censor, T. Elfving, A multiprojection algorithm using Bregman projection in a product splace, Numer. Algorithms, 8(1994), 221-239. 
[2] C. Byrne, Iterative oblique projection onto convex subsets and the split feasibility problems, Inverse Problem, 18(2002), 441-453.

[3] Y. Censor, T. Elfving, N. Kopf, T. Bortfeld, The multiple-sets split feasibility problem and its applications, Inverse Problem, 21(2005), 2071-2084.

[4] Y. Censor, A.Seqal, The split common fixed point problem for directed operators, J.Convex Anal . 16(2009)587-600.

[5] Y. Censor, T. Bortfeld, B. Martin, T. Trofimov, A unified approach for inversion problem in intensity-modolated radiation therapy, Phys. Med. Biol., 51(2006), 23532365.

[6] Y. Censor, A. Motova, A. Segal, Pertured projections and subgradient projections for the multiple-sets split feasibility problems, J. Math. Anal. Appl., 327(2007), 12441256.

[7] G. Lopez, V. Martin, H. K. Xu, Iterative algorithms for the muitiple-sets split feasibility problem. In: Y. Censor, M. Jiang, G. Wang (eds), Biomedical Mathematics: Promising Directions in Imaging, Therapy Planning and inverse Problems, pp.243279. Medical Physics Publishing, Madison(2009).

[8] A. Moudafi, The split common fixed point problem for demi-contractive mappings, Inverse problem, 26(2010), 055007 (6pp).

[9] A. Moudafi, A note on the split common fixed point problem for quasi-nonexpansive operators, Nonlinear Anal.,74(2011), 4083-4087.

[10] L.Q. Qin, L. Wang, Z.L. Ma, Strong and weak convergence theorems for split common fixed problem of asymptotically quasi-nonexpansive mappings, Pioneer Journal of Advances in Applied mathematics, Vol.3, No.2(2011),111-122.

[11] R.E., Bruck, T. Kuczumow, S. Reich, Convergence of iterates of asymptotically nonexpansive mappings in Banach spaces with the uniform Opial property, Colloq. Math., 65 (1993), 169-179.

[12] X. L. Qin, L. Wang, On Asymptotically Quasi- $\phi$-Nonexpansive Mappings in the Intermediate Sense, Abstract and Applied Analysis, Volume 2012, Article ID 636217, 13 pages.

[13] C.E. Chidume, N. Shahzad, H. Zegeye, Convergence theorems for mappings which are asymptotically nonexpansive in the intermediate sense, Numer. Funct. Anal. Optim. 25 (2004), 239-257.

[14] G.E. Kim, T.H. Kim, Mann and Ishikawa iterations with errors for non-Lipschitzian mappings in Banach spaces, Comp. Math. Appl. 42 (2001), 1565-1570. 
[15] K. K. Tan and H. K. Xu, Approximating fixed points of nonexpansive mappings by the Ishikawa iteration process, Journal of Mathematical Analysis and Applications, 178 (2) (1993), 301-308.

Received: May 9, 2013 